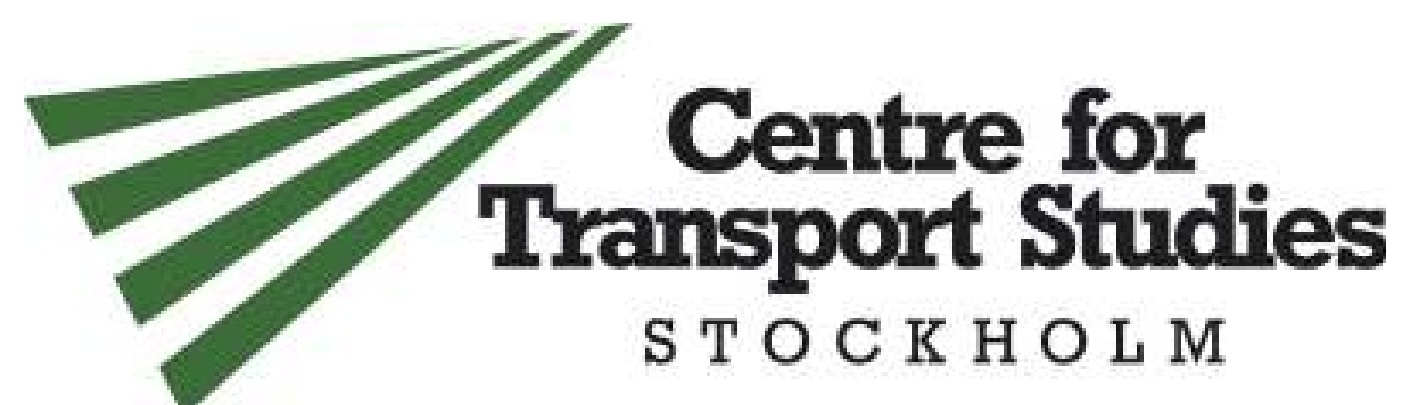

\title{
Inter-temporal variation in the travel time and travel cost parameters of transport models
}

\author{
Maria Börjesson. PhD \\ Centre for Transport Studies, Royal Institute of Technology, SE-100 44 Stockholm \\ maria.borjesson@abe.kth.se
}

CTS Working Paper 2012:16

\begin{abstract}
The parameters for travel time and travel cost are central in travel demand forecasting models. Since valuation of infrastructure investments requires prediction of travel demand for future evaluation years, inter-temporal variation of the travel time and travel cost parameters is a key issue in forecasting. Using two identical stated choice experiments conducted among Swedish drivers with an interval of 13 years, 1994 and 2007, this paper estimates the inter-temporal variation in travel time and cost parameters (under the assumption that the variance of the error components in the indirect utility function is equal across the two datasets). It is found that the travel time parameter has remained constant over time but that the travel cost parameter has declined in real terms. The trend decline in the cost parameter can be entirely explained by higher average income level in the 2007 sample compared to the 1994 sample. The results support the recommendation to keep the travel time parameter constant over time in forecast models, but to deflate the travel cost parameter with the forecasted income increase among travellers and the relevant income elasticity of the cost parameter. Evidence from this study further suggests that the intertemporal and the cross-sectional income elasticities of the cost parameter are equal. The average elasticity is found to be $-0.8--0.9$ in the present sample of drivers, and the elasticity is found to increase with the real income level, both in the cross-section and over time.
\end{abstract}

Keywords: travel demand forecasting; income elasticity; marginal disutility; time parameter; cost parameter; replicated survey

JEL Codes: D61, R41, R42, C25, J22 
Inter-temporal variation in the travel time and travel cost parameters of transport models 


\section{INTRODUCTION}

Infrastructure investments and transport planning are of long-term nature and evaluation therefore often requires forecast horizons of up to 30 years. Such forecasts rely on the crucial assumption that the transport model's parameters, often estimated based on cross-sectional data, are transferable over time, i.e. that a model that presently describe travel behavior can be used to predict travel behavior in a forecast year. Temporal model transferability received much attention some decades ago (Train (1978), Silman (1981), McCarthy (1982), Badoe and Miller (1995), Karasmaa and Pursula (1997) and Gunn (2001)), but has received less attention in more recent years (Fox and James, 2010) in spite of its crucial importance.

The literature finds a general support for temporal transferability of transport models over 5 years (for a review, see Fox and James (2010)). Temporal transferability over longer time periods are less studied. But the two studies that do investigate transferability over 20 years, both based on data from Toronto (Fox, 2011; Badoe and Miller, 1995), give a general support for transferability, although Fox finds that transferability is significantly better over 10 years than over 20 years. Fox (2011) and Silman (1981) also both find that forecasts tend to improve with a better model specification, suggesting that this is because estimates of the key parameters, travel time and travel cost, improve in more detailed models. In particular Fox finds that in-vehicle time parameters are relatively stable over time, whereas this is more unclear with regard to the cost parameter.

This paper deals explicitly with the temporal transferability of the key parameters in transport models: the travel time and travel cost parameters (corresponding to the marginal utilities of travel time and travel cost multiplied by a scale parameter) and how they should be adjusted over time. It is based on analysis of data from two essentially identical stated choice surveys carried out in 1994 and 2007, designed to measure the trade-off between travel time and travel cost. In a replicated SP study, it is easier to focus on transferability of the time and cost parameters in particular, and possibly also to control the study by holding the data collection method unchanged over time, than in large scale transport models based on revealed preference studies.

The first survey was carried out in 1994 as a part of the Swedish value of time study (Algers et al., 1995). A replication of this survey for drivers was carried out in 2007. Care was taken to use exactly the same questionnaire and survey method as in 1994. The sampling of drivers and the design of the stated choice experiment was exactly the same, with one exception: the cost levels were increased by 38 per cent, approximately corresponding to the nominal income growth (including inflation of 14 per cent) in Sweden as a whole between 2007 and 1994 (Statistics Sweden, 2009).

According to the theory of the value of travel time, as originally developed by Becker (1965), DeSerpa (1971), Evans (1972), Jara-Díaz (2003) and Jara-Diaz and Guevara (2003), the value of time equals the wage rate minus the direct value of time. It is also well-known in the field of transport economics that empirically estimated values of time tend to increase with income in cross-sectional samples (Wardman, 2001a, Amador et al., 2005; Hess et al, 2005; Fosgerau, 2006; Cirillo and Axhausen, 2006; Axhausen et al., 2008; Cherchi and Ortúzar, 2010; Ramjerdi, 2011; Abrantes and Wardman, 2012; Börjesson and Eliasson 2012; Román et al., 2012). 
A natural hypothesis is that the value of time increases with income because the marginal disutility of travel cost decreases with income. There are many empirical studies based on cross-sectional data supporting this hypothesis, of which Train and McFadden (1978) is one of the first. They show that mode choice model formulations where the cost parameter is divided by the wage and formulations where the travel time parameter is multiplied by the wage are both microeconomically consistent. Using a Cobb-Douglas function they find, however, that the former formulation is more consistent with their data.

In most forecasting models (see for instance the Swedish national forecasting model (Beser and Algers, 2002)), the time parameter is assumed to remain stable over time and the cost parameter is assumed to decrease over time due to income growth among travellers. There are, however, also forecasting models assuming that the time parameter increases over time due to general income growth but that the travel cost parameter remains constant (see for instance the T/RIM, a regional forecast model for Stockholm (Engelson and Svalgård, 1995)). Before this study, there is little empirical support for either practice; there is no strong reason why the empirical evidence found in analyses of cross-sectional data should hold over time. This study explores whether the travel cost parameter, the travel time parameter or both vary over time. For exclusive interest in evolution of the value of time for appraisal purposes, this is less of an issue ${ }^{1}$, but for implementation in forecasting models it is central.

It is possible that both the marginal disutility of travel cost and marginal utility of travel time change over time, either because real incomes grow or for other reasons. Whether the marginal disutility of travel time can be expected to change over time for other reasons than income growth has been a source of debate. The marginal disutility of travel time is composed of the direct disutility of time spent travelling and the opportunity cost of travel time (De Serpa, 1971). Gunn et al. (1999) and Tapley et al. (2007) discuss some possible causes for inter-temporal variation in these two components of marginal disutility of travel time. They mention increasing ability to use travel time productively, comfort improvements, worsening travel conditions and longer or shorter working hours.

Only three previous studies have repeated stated choice surveys at two points in time in order to estimate the inter-temporal variations in the value of time using the same questionnaire and survey method. All three sampled drivers. The first was carried out in the Netherlands in 1988 and 1997 (reported in Gunn et al., 1999), the second study in Britain 1985 and 1994 (reported in Wardman 2001b) and the third study in Britain 1994 and 2006 (Tapely et al. 2007).

The first study found that the travel cost parameter had remained stable within each real income group but also a significant decline in the travel time parameter. The income increase was large enough to cancel out the decline in the travel time parameter, such that the value of time in real terms remained unchanged between the survey years. The second and third studies found the puzzling result of a slight decline in the value of time, spite of a real income increases. Like the first study, the second and third thus suggest a trend decline in marginal disutility of travel time. None of the three studies focused explicitly on the inter-temporal variation travel time and travel cost parameters, but rather on the inter-temporal variation in the value of time.

\footnotetext{
${ }^{1}$ Variations in marginal utility of money and time in the population may be relevant in appraisal in the specific decision context of prioritizing infrastructure investment projects financed with tax money, see Mackie et al (2001)
} 
Inspired by model development pioneered by Beesley (1965) and Cameron and James (1987), Fosgerau (2006) proposes a model specification for estimation of the value of time directly, and not as a ratio between the time and cost parameters. Börjesson et al. (2012a) have analysed the same data as used in the present study (i.e. two essentially identical stated choice surveys carried out in 1994 and 2007) using the Fosgerau formulation to explore the evolution of the value of travel time over time and its relation to income. They show that the value of time has increased over time, and that the increase is entirely explained by higher incomes in the 2007 sample. Since the value of time is estimated directly in that specification, however, Börjesson et al. (2012a) provide no direct insight related to trends in time and cost parameters to be used in forecasting models, which is the focus of the present paper.

The paper is organized as follows. Section 2 introduces the model. Section 3 describes the study methodology including data collection and model specifications. Section 4 presents estimation results and section 5 concludes.

\section{THE MODEL}

Assume that respondents choose between two trip alternatives differing with respect to travel cost, $c$, and travel time, $t$. Assume that respondents face one base alternative and one modified alternative. In the latter, the travel cost and travel time has been changed in different directions from the time and cost of the base alternative. Denote the variables of the base alternative $\left(c_{B}, t_{B}\right)$ and of the modified alternative $\left(c_{M}, t_{M}\right)$, and define $\Delta c=c_{B}-c_{M}$ and $\Delta t=t_{B}-t_{M}$. Let $y$ be an indicator variable which is 1 if the respondent chooses the base alternative and 0 otherwise. The traditional way to estimate the travel time and cost parameters is to assume an observed marginal utility on the form:

$$
V=\alpha c+\beta t
$$

where $\alpha$ and $\beta$ can be interpreted as marginal disutilities of travel time and cost, respectively. The ratio $\beta / \alpha$ is the value of time, i.e. the marginal rate of substitution (MRS) between time and money. We can estimate the parameters by applying the model2:

$$
y=1\{\alpha \Delta c+\beta \Delta t>\theta+\varepsilon / \mu\}
$$

where $\theta+\frac{\varepsilon}{\mu}$ is the error term (including response errors and omitted explanatory variables). If $\varepsilon$ is taken to be iid standard logistic, a logit model results. The parameter $\mu$ is a scale parameter inversely proportional to the variance of the error term and $\theta$ captures the average of the error term. Note that this model has four degrees of freedom $(\alpha, \beta, \theta$ and $\mu)$, but only three of these can be estimated. Intuitively, the three degrees of freedom stem from three sources: the ratio of the time and cost parameter (the value of time), the variance of the error term (the variance of the omitted variables) and the mean of the error term (the average of the omitted variables). The standard way to identify the model is to multiply the left and the right hand side of the inequality sign in (2) with $\mu$ and then estimate the parameters $\mu \alpha$ and $\mu \beta$ and $\mu \theta$.

Assume now that there are two data sets based on identical stated choice experiments but collected in two waves, year 1 and year 2 . The data set is not a panel such that the

\footnotetext{
${ }^{2} 1\{x>y\}$ is defined to take the value 1 if $x>y$ and 0 otherwise.
} 
waves comprise different individuals. Since the parameters estimated by model (2) is the parameters $\mu \alpha$ and $\mu \beta$ it is not possible to compare $\alpha$ and $\beta$ across the year-specific models unless making any assumption concerning how the scale parameter $\mu$ differ between them. If no such assumption is made, only the ratios $\beta / \alpha$ (the value of time) can be compared.

The aim of this paper is to achieve some guidance on how to adjust the travel time parameter, $\mu \alpha$, and travel cost parameter, $\mu \beta$, over time in transport models. In transport models the scale $\mu$ is assumed to be kept constant over time. For this reason the assumption that the $\mu$ is equal in the two year-specific models is made in this paper, although formally it is impossible to distinguish a change in a multiplicative factor of $\alpha$ and $\beta$ between the years from a change in $\mu$. The aim of this paper is thus not primarily to explore how $\alpha$ and $\beta$ change over time, since these are not observable, but rather how the corresponding time and cost parameters $\mu \alpha$ and $\mu \beta$ change.

Since the scale parameter $\mu$ is assumed to be equal in the year-specific models defined by (2), the year-specific models are estimated simultaneously, applying the specification:

$y=1\left\{\alpha_{1} \Delta c_{1}+\beta_{1} \Delta t_{1}+\alpha_{2} \Delta c_{2}+\beta_{2} \Delta t_{2}>\theta_{1} \delta_{1}+\theta_{2} \delta_{2}+\varepsilon / \mu\right\}$,

where $\delta_{1}$ takes the value one if the observation is collected in the wave 1 and zero otherwise, $\delta_{2}$ takes the value one if the observation is collected in wave 2 and zero otherwise and $\Delta c_{1}=\Delta c \delta_{1}, \Delta c_{2}=\Delta c \delta_{2}, \Delta t_{1}=\Delta t \delta_{1}$ and $\Delta t_{2}=\Delta t_{2} \delta_{2}$.

If the survey techniques, including the recruitment process and experimental designs, are identical the two survey waves (which is the case in the present study), equal variances of the error term, and thus $\mu$, across the year-specific models is a reasonable assumption. Moreover, if the mean of omitted variables captured by $\theta$ (and other parameters added to $\theta$ in the utility function) remains unchanged, this supports the assumption that also the variance of the error term is equal (which is also the case in the present study, as will be shown in the result section). Under the assumption that the scale is $\mu$ is equal in the year-specific models, $\alpha$ and $\beta$ can be compared between year-specific models.

\section{METOD}

\subsection{Data Collection}

The data used in this study was part of the 1994 and the 2007/2008 years Swedish value of time studies (Algers et al, 1995; Börjesson et al, 2012b; Börjesson, 2012). The main Swedish value of time study taking place in 2008 did not use the same survey methods and recruitment process as the 1994 study. To be able to study the evolution of the value of time, travel time parameter and travel cost parameter over time, a virtually identical replication of the 1994 study was carried out for drivers in 2007, in addition to the main study taking place in 2008. The present study uses the 1994 the 2007 samples, both comprising private tips for drivers. The 2007 replication was collected using exactly the same questionnaire and survey design as in 1994, except that the cost level in the stated choice design was adjusted in the 2007 design, see below.

The principal recruitment method both years was to first register license plate numbers at selected road sections. The registration numbers were then matched with names, addresses and phone numbers of the car owners. The 1994 value of time study 
concentrated on regional and long distance trips, and for this reason the selected road sections were larger roads outside cities/towns in all parts of Sweden. Hence, the recruited trips are not representative for all private car trips in Sweden. The same road sections were selected in the 1994 and the 2007 survey waves. The registration of license plate numbers took, both years, place in the period of November 15 to October 1 , equally distributed among all days of the week at 7 am to $7 \mathrm{pm}$.

The respondents were invited to participate in the survey by a letter sent by regular mail to the car owner as soon as the car had been observed. The owners also received a survey questionnaire where details of the observed trip could be filled in (as a help to remember) and sheets for the stated choice interview. The car owners were then contacted by telephone, repeatedly until reached but at most seven times. A computer aided interview was then undertaken on an agreed day with the person who was driving the car when it was observed.

The interview included socio-economic information of the respondent and her household, details about the observed trip and a stated choice experiment comprising choices between alternatives differing in two dimensions: travel time and travel cost (see further below). To see these alternatives, respondents were asked to fill travel times and travel costs read to them over the telephone in the mailed sheets. The stated choice experiment was generated by a computer program based on the observed trip to give the experiment a realistic context. The average interview length was 15 minutes.

The share of cars owned by companies but used by private persons, for which it is more difficult to match telephone numbers to the drivers, has increased substantially between the survey years ${ }^{3}$. In 1994, 15 per cent of the recruited drivers could not be reached, while in 2004 this share had increased to 40 per cent ${ }^{4}$. Of all trips where the driver was reached, the 1994 response rate was 79 per cent (17 per cent declined to participate and 4 per cent were unable to participate because of language problems or poor hearing). In 2007, the corresponding rate was 60 per cent ( 34 per cent declined to participate and 6 per cent were unable to participate because of language problems or poor hearing).

\subsection{Experimental design}

The stated choice experiment comprised 8 choices between alternatives differing with respect to travel time and travel cost. The respondents faced one base alternative and one alternative for which the travel cost and travel time had been changed in different directions. Hence, the design contained no dominant alternatives. The base alternative remained constant within each individual. Figure 1 shows the nature of the choices facing the interviewees. The respondents were asked to state which of the two alternatives they would prefer. They had also the option to respond that "both alternatives are equally good".

\footnotetext{
${ }^{3}$ In both survey waves a predetermined share of company owned cars were recruited. In 1994, 20 per cent (more than the actual share on the road) of the recruited cars was owned by companies and 90 per cent of these was business trips and is thus not included in the analysis in this paper. In 2007, 17 per cent of the recruited cars were company-owned cars; this share was taken from the national travel survey and reflects the accrual share on the road.

${ }^{4}$ This is partly because the numbers to mobile phones are not available to the same extent as the numbers for fixed telephones in Sweden. The use mobile phones have increased and while fixed telephone subscriptions have decreased substantially between the survey years. Other surveys, for instance the national travel survey experience the same problem.
} 
Travel times and travel costs of the base alternative were constructed from the time and cost of the reference trip (the recruitment trip). The travel distance was converted to travel cost in the base alternative by assuming an average marginal cost of driving of $€ 0.13$ per km (nominal) in 1994 and €0.18 per km (nominal) 2007. These marginal driving costs were calculated and used (at the relevant years) by the Swedish Tax Agency, and corresponds exactly to the increase in consumer price index between the years. Respondents were asked to think of the reference trip situation while stating their choices.

At the time of the first wave of data collection, 1994, earlier evidence had suggested that a base alternative which corresponds exactly to the reference trip could lead to inertia bias, i.e. that respondents would tend to escape to the "no change" choice (this is discussed further later on). To reduce this problem, the base alternative was formed by randomly multiplying the reference travel time and travel cost by 0.9 or 1.1 . Moreover, to avoid attaching any greater importance to the base alternative, the base alternative was referred to as the " $C$ " alternative rather than the " $A$ " alternative. The " $C$ " alternative was then to be compared to different alternatives randomly denoted $A, B, D$, E etc. The time and cost differences in each choice were taken from a fixed schedule, chosen based on the reference travel time and distance.

Identical experimental designs were used in the two survey years, with the exception that the cost levels were increased 38 per cent in the 2007 design. Table 1 summarises the characteristics of the design and the reference trip in the final estimation samples. (The costs are given in Euros converted from Swedish Kronor using the conversion rate 0.1 in the table and throughout this paper.)

To make it possible to capture the well-known gap between valuation of gains and losses, the design comprises two types of choices, namely 'willingness to pay' (WTP) choices and 'willingness to accept' (WTA) choices. The WTP-choice is presented as a choice between the base alternative and a faster but more expensive alternative. The WTA-type of choice is the opposite, including the base alternative and one slower but less expensive alternative. The two types of choices were presented equally often (4 times each). The first choice was randomly of WTP- or WTA-type, to avoid bias due to anchoring to the initial choice.

When exploring how the time and cost parameters have developed over time, the possibility that differences in the stated choice design between the waves induce differences in the parameters should be considered. As mentioned, Börjesson et al. (2012a) estimates the value of time using the present data by applying the econometrical model proposed by Fosgerau (2006). They parameterise the value of time as $V T T=V T T_{0} \exp \left(\gamma \log d_{\text {ref }}+\tau \log t_{\text {ref }}+\kappa \log \Delta t\right)$ where $V T T_{0}$ includes some covariates irrelevant here (a constant, a dummy variable for WTP type choice and income), $d_{r e f}$ is the reference travel distance, $t_{r e f}$ is the reference travel time and $\Delta t$ is the difference in travel time between the base alternative and the modified alternative in the stated choice experiment. The travel distance elasticity of the value of time is $\gamma$ (estimated to 0.48), the time elasticity is $\tau$ (estimated to -0.49) and the time difference elasticity is $\kappa$ (estimated to 0.55 ).

According to Table 1, the average reference time is 5 per cent higher in the 2007 sample; the average reference distance is 1 per cent higher and the travel time difference $\Delta t$ is on average 7 per cent higher in the 2007 sample.

According to the model above, these changes would, all else equal, imply that a ratio of $e^{(0.48 \log 1.01-0.49 \log 1.05+0.55 \log 1.06)}=1.02$, between the 2007 and the 1994 value of time. Hence, 
the increase in the mean travel distance, travel time and $\Delta t$ in the choice design almost cancels out and increases the value of time only about 2 per cent (which is neglected in the further analyses).

Table 1: Summary of the stated choice design and the reference travel times and distances in the 1994 and 2007 final estimation samples.

\begin{tabular}{|l|r|r|r|r|}
\hline & First quartile & Median & Mean & Third quartile \\
\hline Travel time diff 1994 (min) & 5 & 10 & 17.2 & 20 \\
\hline Travel time diff 2007 (min) & 5 & 10 & 18.4 & 25 \\
\hline Travel cost diff 1994 (€) & 3 & 5 & 12.9 & 15 \\
\hline Travel cost diff 2007 (€) & 4 & 8 & 19.0 & 21 \\
\hline Ref. travel time 1994 (min) & 30 & 48 & 107.7 & 120 \\
\hline Ref. travel time 2007 (min) & 30 & 55 & 112.7 & 150 \\
\hline Ref. travel distance 1994 (km) & 26 & 55 & 124.7 & 140 \\
\hline Ref. travel distance 2007 (km) & 20 & 50 & 126.4 & 180 \\
\hline
\end{tabular}

\begin{tabular}{|c|c|}
\hline Alternative $\mathrm{C}$ & Alternative A, B, D,... \\
\hline Travel time $45 \mathrm{~min}$ & Travel time is 5 minutes longer \\
Travel cost $€ 5$ & Travel cost is $€ 1$ less \\
\hline
\end{tabular}

Figure 1: Survey question.

\subsection{Descriptive statistics}

The 1994 sample comprised interviews with 644 individuals and the 2007 sample comprised interviews with 564 individuals. Discarding individuals who did not pay the trips themselves, 4518/4159 (from 1994/2007, respectively) observations from $566 / 522$ individuals remained. The observations where the "both are equally good" alternative was chosen were discarded, leaving 4321/3627 observations from 563/504 individuals 5 .

In models where income is included, individuals who have not reported income are discarded, leaving 4107/3455 observations from 535/478 individuals (the total for both years is 7562 observations from 1013 individuals).

In the final estimation samples, the average real after-tax income is 43 per cent higher in the 2007 wave than in the 1994 wave (63 per cent in nominal terms). During the

\footnotetext{
${ }^{5}$ These observations would not have had to be discarded if applying an ordered logit model in the estimation. However, it is not possible to have panel effects in an ordered logit model in Biogeme (Bierlaire, 2003), and for this reason the observations are removed.
} 
same period the real after-tax income growth per capita in Sweden a whole has been lower, about 21 per cent (Statistics Sweden, 2009).

The gap between the income growth per capita in Sweden as a whole and the income increase observed in the 1994 and 2007 samples may have several causes. First, the definition of income in the survey questionnaires includes income from labour, study allowances and pension, but not other subsidies, such as extra allowances for children or income from capital. Official income statistics, however, include all types if income. Second, drivers were recruited at some particular points (but the same point both survey years). Hence, local and regional differences in income growth may have caused a gap between income difference in the sample waves and the income growth in Sweden as a whole. Third, the target population in the survey, namely drivers on the selected road links, may be different from the average Swedish population in terms of income growth.

Figure 2 compares the distributions of real incomes in the two survey waves. As shown in Table 2, most socioeconomic variables except income remain largely unchanged but the share of retired drivers has increased. The share of service or shopping trips has increased at the expense of commuting trips.

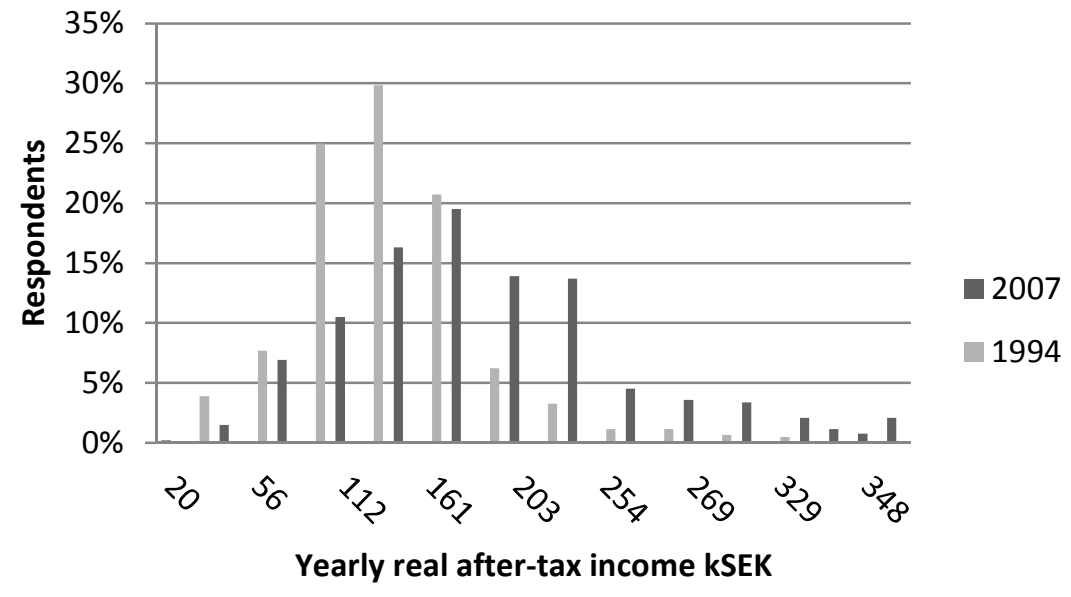

Figure 2: Nominal income distribution. 
Inter-temporal variation in the travel time and travel cost parameters of transport models

Table 2: Summary of the stated choice design and the reference travel times and distances in the 1994 and 2007 final estimation samples

\begin{tabular}{|c|c|c|c|c|c|c|}
\hline & $\begin{array}{r}\text { Mean } \\
1994\end{array}$ & $\begin{array}{c}\text { Min } \\
1994\end{array}$ & $\begin{array}{l}\text { Max } \\
1994\end{array}$ & $\begin{array}{r}\text { Mean } \\
2007\end{array}$ & $\begin{array}{r}\text { Min } \\
2007\end{array}$ & $\begin{array}{l}\text { Max } \\
2007\end{array}$ \\
\hline Female (share) & 0.42 & & & 0.36 & & \\
\hline Employed (share) & 0.69 & & & 0.70 & & \\
\hline Employed, flexible hours (share) & 0.26 & & & 0.32 & & \\
\hline Retired (share) & 0.17 & & & 0.24 & & \\
\hline Commuting (share) & 0.29 & & & 0.19 & & \\
\hline Recreation/Social/Give ride (share) & 0.37 & & & 0.36 & & \\
\hline Service/Shopping (share) & 0.19 & & & 0.30 & & \\
\hline School (share) & 0.02 & & & 0.01 & & \\
\hline Important not to be late (share) & 0.25 & & & 0.28 & & \\
\hline Age (years old) & 47 & 19 & 83 & 52 & 19 & 87 \\
\hline \# working hours per week & 41 & 22 & 84 & 41 & 22 & 80 \\
\hline \# of employed in household & 1.43 & 0 & 5 & 1.39 & 0 & 4 \\
\hline
\end{tabular}




\subsection{Model specifications}

This sub-section formulates a series of econometric models, which all include yearspecific parameters for travel time and cost. The key issue of the model estimation is to explore how the time and cost parameters differ between the years. A number of different model specifications are employed in order to explore the robustness of the findings. The first five specifications are multinomial logit models (MNL) and the last four models are mixed logit models (MXL). The MXL models include treatment of the 'repeated measures' property of stated choice data, which is unaccounted for in the MNL models. This property implies, if unaccounted for, underestimation of the standard error of the parameter estimates but not any major bias in the central estimates of the parameters themselves (Cirillo, 2000) ${ }^{6}$. All models are kept reasonably simple for the sake of generality and because the sample sizes are not large enough to allow comparison of a large number of year-specific parameters across years.

\section{Specification of model A}

The variables of the base and modified alternatives are $\left(c_{B}, t_{B}\right)$ and $\left(c_{M}, t_{M}\right)$. Define $\Delta c=c_{B}-c_{M}$ and $\Delta t=t_{B}-t_{M}$, and let $y$ be an indicator variable which is 1 if the respondent chooses the base alternative and 0 otherwise. The simplest model that is estimated is based on the model defined in (2), and takes the form:

$y=1\left\{\alpha_{94} \Delta c_{94}+\beta_{94} \Delta t_{94}+\alpha_{07} 94 \Delta c_{07}+\beta_{07} \Delta t_{07}>\varepsilon / \mu\right\}$,

where $\varepsilon$ is taken to be iid standard logistic, such that a logit model results and $\mu$ is a scale parameter inversely proportional to the variance of the error term. $\delta_{94}$ takes the value 1 if the observation is in the 1994 sample and zero otherwise, $\delta_{07}$ takes the value 1 if the observation is in the 2007 sample and zero otherwise. Given this, we define $\Delta t_{94}=\Delta t \delta_{94}, \Delta t_{07}=\Delta t \delta_{07} . \Delta c_{94}=\Delta c \delta_{94}$ and $\Delta c_{07}=\Delta c \delta_{07} / i$, where $i=1.14$ deflates the costs according to the growth of consumer price index $1994-2007$. As discussed in section 2 , it is assumed that the scale parameter $\mu$ is equal across years, but all other parameters in (3) are year-specific. The model defined in (3) therefore estimates two year-specific models simultaneously under the assumption that $\mu$ is equal across them.

The key point of interest in the estimation of model $A$ is to explore if $\mu \alpha_{94}$ and $\mu \alpha_{07}$ are significantly different and if $\mu \beta_{94}$ and $\mu \beta_{07}$ are significantly different.

\section{Model specification B}

Choice experiments need to relate to a real-world reference situation in order to reduce hypothetical biases, which are why the present data contains a base alternative, close to the respondent's reference trip in terms of time and cost, and a modified alternative. However, the fact that the choice experiment is framed as a variation around a reference situation and the presence of loss aversion (losses matter more than equally sized gains) give rise to phenomena such as inertia, WTP/WTA-gap, undervaluation of

\footnotetext{
6 The maximum of the log-likelihood function is not affected whether the serial correlation between observations from the same individuals is taken into account or not. However, when the serial correlation is not taken into account, the efficiency of the estimation will decrease. This means essentially, that the estimates get more imprecise when not taking account of the serial correlation, given the number of observations. Hence, for small sample sizes, this may give rise to errors, because the accuracy declines as the estimation become less efficient.
} 
small time savings and endowment effects (which are essentially the same phenomena appearing under different names).

Inertia refers to the fact that the respondents, all else equal, have a tendency to choose the base alternative close to the reference. The WTP/WTA-gap, i.e. that the respondents value travel time losses higher than travel time gains of the same absolute magnitude, is observed by many studies (for an overview see Daly et al. (2012)). The WTP/WTAgap can be explained by loss aversion (Bateman et al., 1997). The common finding that the valuation per minute of small travel time savings is smaller than of larger travel time savings in stated choice experiments (Mackie et al. 2001; Fowkes 1999; Hultkrantz and Mortazavi, 2001; Fosgerau, 2006; Bates and Whelan, 2001; Börjesson and Eliasson; 2012) could be explained by loss aversion (Hjorth and Fosgerau, 2011).

Inertia is captured in model specification B by adding a dummy parameter for the base alternative, one for each year-specific sample, denoted $\theta_{B 94}$ and $\theta_{B 07}$, such that the model takes the form:

$y=1\left\{\theta_{B 94} \delta_{94}+\theta_{B 94} \delta_{94}+\alpha_{94} \Delta c_{94}+\beta_{94} \Delta t_{94}+\alpha_{07} \Delta c_{07}+\beta_{07} \Delta t_{07}>\varepsilon / \mu\right\}$,

This paper does not explore the causes of the inertia bias, but focus primarily on how the parameters in the model, including $\mu \theta_{B 94}$ and $\mu \theta_{B 07}$ differ between the years.

\section{Model specification C}

Model specification C controls for the WTP-WTA gap by adding travel time and cost parameters specific for WTA choices to the utility function. These are assumed to be constant across years, implying that the size of loss aversion is assumed to be the same in the year-specific samples.

Moreover, it is possible that the inertia bias is different in WTP and WTA choices, since these phenomena are both arising from reference dependence. Model specification $C$ therefore also includes different inertia parameters in the base alternative for WTP and WTA choices.

$y=1\left\{\theta_{B W T P 94} \delta_{W T P} \delta_{94}+\theta_{B W T P 07} \delta_{W T P} \delta_{07}+\theta_{B W T A 94} \delta_{W T A} \delta_{94}+\theta_{B W T A 07} \delta_{W T A} \delta_{07}+\right.$ $\left.\alpha_{94} \Delta c_{94}+\beta_{94} \Delta t_{94}+\alpha_{07} \Delta c_{07}+\beta_{07} \Delta t_{07}+\alpha_{W T P} \Delta t \delta_{W T P}+\beta_{W T P} \Delta c \delta_{W T P}>\frac{\varepsilon}{\mu}\right\}$,

where $\delta_{W T P}$ equals one for WTP choices and zero otherwise. The parameters $\alpha_{W T P}$ and $\beta_{W T P}$ are additional marginal utilities for time and cost for WTP choices.

\section{Model specification D}

Model specification D is identical to specification C, but the inertia parameters are not year-specific:

$y=1\left\{\theta_{B W T P} \delta_{W T P}+\theta_{B W T A} \delta_{W T A}+\alpha_{94} \Delta c_{94}+\beta_{94} \Delta t_{94}+\alpha_{07} \Delta c_{07}+\beta_{07} \Delta t_{07}+\right.$

$\left.\alpha_{W T P} \Delta t \delta_{W T P}+\beta_{W T P} \Delta c \delta_{W T P}>\frac{\varepsilon}{\mu}\right\}$,

This specification investigates whether the model fit deteriorates when constraining the inertia parameters to be equal across years.

\section{Model specification E}


Model specification $\mathrm{E}$ is identical to specification $\mathrm{D}$, but estimates year-specific additional marginal utilities for time and cost for WTP choices:

$y=1\left\{\theta_{B W T P} \delta_{W T P}+\theta_{B W T A} \delta_{W T A}+\alpha_{94} \Delta c_{94}+\beta_{94} \Delta t_{94}+\alpha_{07} \Delta c_{07}+\beta_{07} \Delta t_{07}+\right.$

$\left.\alpha_{W T P 94} \Delta t \delta_{W T P} \delta_{94}+\alpha_{W T P 07} \Delta t \delta_{W T P 07}+\beta_{W T P 94} \Delta c \delta_{W T P 94}+\beta_{W T P 07} \Delta c \delta_{W T P 07}>\frac{\varepsilon}{\mu}\right\}$,

This specification investigates whether the model fit improves significantly when introducing year-specific additional parameters for marginal utilities for time and cost for WTP choices.

\section{Model specification F}

In specification $\mathrm{F}$ random time and cost parameters are introduced. As mentioned, the "repeated measures" property is accounted for by assuming that the random parameters are individual specific. Model $\mathrm{F}$ uses the specification of model $\mathrm{C}$, but the parameters $\left(\beta_{07}, \beta_{94}, \alpha_{07}, \alpha_{94}\right)$ are taken to be normally distributed in the population, specified by one mean and a standard deviation each.

\section{Model specification G}

Since an a priori expectation is that the cost parameter has attenuated over time because the real income has increased, model specification $G$ explicitly estimates the income elasticity of the marginal disutility of travel cost, $a$. The income elasticity of the cost parameter is also very important in the forecasting context.

After tax income is denoted $Y$. In the 2007 sample income is deflated in line with the growth of consumer price index 1994-2007, 14 per cent:

$y=1\left\{\theta_{B W T P} \delta_{W T P}+\theta_{B W T A} \delta_{W T A}+\alpha \Delta t+\beta_{W T P} \Delta c \delta_{W T P}+\beta_{94} \mathrm{Y}^{\mathrm{a}} \Delta c_{94}+\beta_{07} \mathrm{Y}^{\mathrm{a}} \Delta c_{07}+>\right.$
$\left.\frac{\varepsilon}{\mu}\right\}$,

In this specification the parameter $\beta_{W T A}$ is taken out (because it proved to be insignificant, see section 4).

\section{Model specification $\mathbf{H}$}

Model specification $\mathrm{H}$ estimates different cost parameters and income elasticities of the cost parameter for respondents above and below the median income ( $Y_{\text {Median }}$ is the pooled median for both samples, $13.5 \mathrm{k} € /$ year after tax in price level 1994)::

$y=$

$1\left\{\theta_{\text {interiaWTP }} \delta_{W T P}+\theta_{\text {interiaWTA }} \delta_{W T A}+\alpha \Delta t+\beta_{W T P} \Delta c \delta_{W T P}+\beta_{\text {Inc } 1} Y^{a_{\text {inc } 1}} \Delta c \delta_{\text {inc } 1}+\right.$

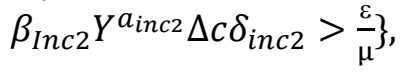

where $\delta_{\text {inc1 }}$ takes the value 1 if $Y<Y_{\text {median }}$ and 0 otherwise, and $\delta_{\text {inc2 }}$ takes the value 1 if $Y \geq Y_{\text {median }}$ and 0 otherwise. $\beta_{\text {Inc1 } 1}$ and $a_{\text {Inc1 }}$ refer to respondents below the median income and $\beta_{\text {Inc } 2}$ and $a_{\text {Inc2 } 2}$ refer to respondents with median income or above. These parameters are restricted to be constant across years.

\section{Model specification I}


Model specification I includes year-specific income elasticities, $a_{07 \text { Inc1, }} a_{07 \text { Inc2, }} a_{94 \text { Inc } 1}$ and $a_{94 I n c 2}$, to explore if the income elasticity of the marginal disutility of travel cost remains stable at each real income level:

$y=1\left\{\theta_{B W T P} \delta_{W T P}+\theta_{B W T A} \delta_{W T A}+\alpha \Delta t+\beta_{W T P} \Delta c \delta_{W T P}+\beta_{I n c 1} Y^{a_{94 i n c 1}} \Delta c \delta_{i n c 1}+\right.$

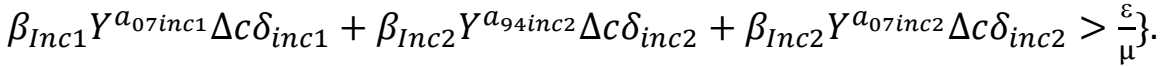

\section{ESTIMATION RESULTS}

Parameters of specifications A-E are shown in Table 3 and parameters of specification F-I are shown in Table 4.

\section{Model specification A}

The only change between the years is that of the cost parameter - but the t-statistic for the difference $\mu \beta_{07}-\mu \beta_{94}$ is only 1.41 , which is not statistically significant. Note, however, that in nominal terms (not deflating the costs in the 2007 sample 14 per cent), $\mu \beta_{07}-\mu \beta_{94}$ has t-value 2.63 and is thus significantly different from zero. Hence, this lends at least some support for a trend decline in the cost parameter. The time parameters remain very similar across the years.

The implied value of time (VTT) of the model is within the normal range: $7.7 € / \mathrm{h}$ for $19949 € / h$ for 2007 (in price level 1994).

\section{Model specification B}

The inertia parameters in model $\mathrm{B}, \mu \theta_{B}$, are significant (with a size equivalent to 9 minutes of travel time). Interestingly, also the inertia parameters remain stable between years. As in specification $A$, only the cost parameter changes between the years. The t-statistic for the difference $\mu \beta_{07}-\mu \beta_{94}$ is 1.58 and the travel time parameters remain very similar between the two years.

\section{Model specification C}

The parameter $\beta_{W T P}$ is very close to zero and insignificant, whereas the $\alpha_{W T P}$ is significantly larger than zero, implying that the marginal disutility of time is lower in WTP choices than in WTA choices. Hence, more loss aversion is found in the time dimension than in the cost dimension, which is consistent with the finding of De Borger and Fosgerau (2008).

The inertia bias is only positive in WTP choices. In WTA choices a small bias working in the opposite direction is found, implying that in WTA-choices there is a tendency to choose the non-base alternative. In other words, there is an extra utility attached to the alternative with longer travel time and lower cost. For this reason, the value of time (computed as a geometrical average of WTA and WTP, which is the reference-free value of time according to De Borger and Fosgerau (2008)) implied by this model is larger than those implied by model B, in which inertia parameters are restricted to be the same for WTP and WTA choices.

Signs and sizes of the inertia parameters remain stable across years. The observation that the parameters for marginal disutility of travel time, inertia and loss aversion remain stable supports the hypothesis that the response scale $\mu$ is indeed similar in the two year-specific samples. 
The key point of interest here is still to compare the estimated marginal utilities of time and cost across the years. The comparison gives a similar result as given by the previous models: the marginal disutility of time remains stable and the t-statistic of $\mu \beta_{07}-\mu \beta_{94}$ is 1.53 . 
Table 3: Model estimates of specifications A-E.

\begin{tabular}{|c|c|c|c|c|c|c|c|c|c|c|}
\hline & \multicolumn{2}{|l|}{ Model A } & \multicolumn{2}{|c|}{ Model B } & \multicolumn{2}{|c|}{ Model C } & \multicolumn{2}{|c|}{ Model D } & \multicolumn{2}{|c|}{ Model E } \\
\hline \# par: & & 4 & & 6 & & 10 & & 8 & & 10 \\
\hline \# obs: & & 7948 & & 7948 & & 7948 & & 7948 & & 7948 \\
\hline LL & & 5140.0 & & 5016.5 & & 4909.3 & & 4910.0 & & 4908.1 \\
\hline $\mathrm{Rho}^{2}:$ & & 0.067 & & 0.089 & & 0.109 & & 0.109 & & 0.109 \\
\hline Name & Value & t-test & Value & $\mathrm{t}$-test & Value & t-test & Value & t-test & Value & t-test \\
\hline$\mu \beta_{07}$ & -0.026 & -13.1 & -0.028 & -13.7 & -0.030 & -11.4 & -0.030 & -11.6 & -0.028 & -9.8 \\
\hline$\mu \beta_{94}$ & -0.031 & -13.5 & -0.033 & -14.1 & -0.036 & -12.7 & -0.036 & -12.7 & -0.039 & -11.1 \\
\hline$\mu \alpha_{07}$ & -0.039 & -16.3 & -0.042 & -17.0 & -0.069 & -15.5 & -0.070 & -16.6 & -0.065 & -13.6 \\
\hline$\mu \alpha \alpha_{94}$ & -0.039 & -16.9 & -0.042 & -17.6 & -0.073 & -16.2 & -0.071 & -16.5 & -0.076 & -14.6 \\
\hline \multicolumn{11}{|l|}{$\mu \theta$} \\
\hline$\mu \theta_{B 07}$ & & & 0.370 & 10.4 & & & & & & \\
\hline$\mu \theta_{B 94}$ & & & 0.377 & 11.6 & & & & & & \\
\hline$\mu \beta W T P$ & & & & & 0.001 & 0.3 & 0.001 & 0.3 & & \\
\hline$\mu \alpha_{W T P}$ & & & & & 0.020 & 4.3 & 0.020 & 4.3 & & \\
\hline$\mu \theta_{B W T A}$ & & & & & & & -0.220 & -4.5 & -0.223 & -4.5 \\
\hline$\mu \theta_{B W T P}$ & & & & & & & 0.724 & 15.0 & 0.723 & 15.0 \\
\hline$\mu \theta_{B W T A 07}$ & & & & & -0.189 & -2.8 & & & & \\
\hline$\mu \theta_{\text {BWTA94 }}$ & & & & & -0.244 & -4.0 & & & & \\
\hline$\mu \theta_{B W T P 07}$ & & & & & 0.671 & 9.9 & & & & \\
\hline$\mu \theta_{B W T P 94}$ & & & & & 0.769 & 12.3 & & & & \\
\hline$\mu \beta$ WTA07 & & & & & & & & & -0.003 & -0.7 \\
\hline$\mu \beta W T A 94$ & & & & & & & & & 0.005 & 1.1 \\
\hline$\mu \alpha_{W T P 07}$ & & & & & & & & & 0.012 & 2.1 \\
\hline$\mu \alpha_{W T P 94}$ & & & & & & & & & 0.028 & 4.4 \\
\hline $\begin{array}{l}\text { VTT } 2007 \\
{[€ / h]}\end{array}$ & 9.0 & & 8.9 & & 11.7 & & 12.0 & & 12.1 & \\
\hline $\begin{array}{l}\text { VTT } 1994 \\
(€ / h]\end{array}$ & 7.7 & & 7.6 & & 10.3 & & 10.1 & & 10.1 & \\
\hline $\begin{array}{l}\text { WTA } 2007 \\
(€ / h]\end{array}$ & & & & & 13.7 & & 13.9 & & 14.1 & \\
\hline $\begin{array}{l}\text { WTA1994 } \\
(€ / h]\end{array}$ & & & & & 12.0 & & 11.8 & & 11.8 & \\
\hline $\begin{array}{l}\text { WTP } 2007 \\
(€ / h]\end{array}$ & & & & & 10.0 & & 10.3 & & 10.3 & \\
\hline $\begin{array}{l}\text { WTP } 1994 \\
(€ / h]\end{array}$ & & & & & 8.9 & & 8.7 & & 8.7 & \\
\hline $\begin{array}{l}t \text {-value } \\
\mu \beta_{07-} \mu \beta_{94}\end{array}$ & 1.41 & & 1.58 & & 1.60 & & 1.53 & & 2.46 & \\
\hline $\begin{array}{l}\text { t-value } \\
\mu \alpha_{07}-\mu \alpha_{94}\end{array}$ & -0.06 & & -0.03 & & 0.64 & & 0.18 & & 1.59 & \\
\hline
\end{tabular}

\section{Model specification D}

Restricting the year-specific inertia parameters, as in model D, only decreases the log likelihood value 0.9 compared to model C. The chi-square test thus shows that yearspecific inertia parameters do not significantly improve the model fit. The comparison $\mu \beta_{07}-\mu \beta_{94}$ gives a similar result as given by the previous models: the t-statistic of $\mu \beta_{07}-\mu \beta_{94}$ is 1.60 .

\section{Model specification E}


The pattern that the parameter $\beta_{W T P}$ is significantly smaller than $\alpha_{W T P}$ (and hence that more loss aversion is found in the time dimension than in the cost dimension) remains stable across years. Moreover, the chi-square test shows that model D does not improve significantly when adding year-specific parameters for marginal disutility of time and cost for WTP choices. The comparison $\mu \beta_{07}-\mu \beta_{94}$ gives a similar result as given by the previous model; the t-statistic is 1.60 .

\section{Model specification F}

As expected, the model fit of specification $F$ is considerably better than the corresponding MNL model E. The standard deviations of the time and cost parameters are highly significant. Most importantly, the t-statistic of $\mu \beta_{07}-\mu \beta_{94}$ increases to 2.58. Hence, the decline in the cost parameter becomes significant when the "repeated measures" property is controlled for in the estimation. In model D the 2007 cost parameter is 16 per cent lower than the 1994 cost parameter (in absolute terms). In the corresponding MXL model F, the mean of the 2007 cost parameter is 27 per cent lower.

Although the mean of the cost parameter is smaller in the 2007 sample than in the 1994 sample, the standard deviations of the cost parameters are very similar across years. Both the means and standard deviations of the time parameters remain stable across years.

The inter-temporal income elasticity of the cost parameter implied by model $\mathrm{F}$ is -0.90 : the cost parameters decrease 27 per cent, and the average real income increase of 43 per cent in the 2007 sample compared to the 1994 sample $(\ln (0.73) / \ln (1.43)=-0.90)$.

\section{Model specification G}

The income elasticity of the marginal disutility of cost, $a$, is estimated to -0.46 , which is lower than what is derived from model F (the source of gap could be that, as we will see, this elasticity strongly depends on real income level, which may bias the estimated elasticity if not accounted for). Interestingly, the $\mu \beta$ parameter remains remarkably stable across the years when controlling for income. Hence, the income growth explains the entire decline in the marginal disutility of cost. The fact that the cost parameters remain similar across years when controlling for income differences indicate that the inter-temporal elasticity of the cost parameter is the same as the cross-sectional.

Table 4: Model estimates of specifications F-I.

\begin{tabular}{|c|c|c|c|c|c|c|c|c|}
\hline & Model F & & Model G & & Model H & & Model I & \\
\hline \# par: & 12 & & 10 & & 11 & & 13 & \\
\hline \# obs: & 7948 & & 7562 & & 7562 & & 7562 & \\
\hline \# ind: & 1067 & & 1013 & & 7562 & & 1013 & \\
\hline LL & -4194.6 & & -3953.3 & & -3945.0 & & -3943.7 & \\
\hline Rho': & 0.236 & & 0.244 & & 0.247 & & 0.245 & \\
\hline Name & Value & t-test & Value & t-test & Value & $\mathrm{t}$-test & Value & \\
\hline$\mu \beta_{07}$ & -0.153 & -10.5 & -0.117 & -8.9 & & & & \\
\hline$\mu \sigma_{\beta 07}$ & 0.144 & 8.4 & 0.093 & 7.5 & & & & \\
\hline$\mu \beta_{94}$ & -0.211 & -12.4 & -0.125 & -7.1 & & & & \\
\hline$\mu \sigma_{\beta 94}$ & 0.164 & 11.7 & 0.092 & 5.5 & & & & \\
\hline$\mu \beta_{\operatorname{Inc1}}$ & & & & & -0.168 & -5.1 & -0.170 & -5.1 \\
\hline$\mu \sigma_{\beta I n c 1}$ & & & & & 0.124 & 5.0 & 0.125 & 4.9 \\
\hline
\end{tabular}




\begin{tabular}{|c|c|c|c|c|c|c|c|c|}
\hline$\mu \beta_{\operatorname{Inc2} 2}$ & & & & & -0.077 & -5.1 & -0.082 & -5.6 \\
\hline$\mu \sigma_{\beta} \operatorname{lnc2}$ & & & & & 0.061 & 5.2 & 0.056 & 5.5 \\
\hline$a$ & & & -0.458 & -5.1 & & & & \\
\hline$a_{\operatorname{Inc1}}$ & & & & & -0.278 & -2.2 & & \\
\hline$a_{\text {Inc } 2}$ & & & & & -1.250 & -4.4 & & \\
\hline$a_{07 I n c 1}$ & & & & & & & -0.220 & -1.3 \\
\hline$a_{94 I n c 1}$ & & & & & & & -0.280 & -2.2 \\
\hline a 07 Inc2 & & & & & & & -1.170 & -4.3 \\
\hline$a_{94 \operatorname{Inc} 2}$ & & & & & & & -1.200 & -4.5 \\
\hline$\mu \alpha_{07}$ & 0.240 & 14.5 & & & & & & \\
\hline$\mu \sigma_{\alpha 07}$ & 0.163 & 12.3 & & & & & & \\
\hline$\mu \alpha_{94}$ & 0.244 & 16.8 & & & & & & \\
\hline$\mu \sigma_{\alpha^{94}}$ & 0.150 & 14.7 & & & & & & \\
\hline$\mu \alpha$ & & & 0.24 & 19.2 & 0.242 & 18.4 & 0.245 & 18.8 \\
\hline$\mu \sigma_{\alpha}$ & & & 0.159 & 14.3 & 0.156 & 15.4 & 0.157 & 16.7 \\
\hline$\mu \beta_{W T P}$ & 0.00961 & 1.5 & & & & & & \\
\hline$\mu \alpha_{W T P}$ & -0.0485 & -6.3 & -0.0547 & -8.3 & -0.054 & -8.1 & -0.0539 & -8.2 \\
\hline$\mu \theta_{W T A}$ & -0.472 & -5.1 & -0.401 & -4.1 & -0.403 & -4.1 & -0.422 & -4.4 \\
\hline$\mu \theta W T P$ & 1.13 & 11.6 & 1.04 & 10.4 & 1.050 & 10.3 & 1.06 & 10.6 \\
\hline $\begin{array}{l}t \text {-value } \\
\mu \beta_{07-} \mu \beta_{94}\end{array}$ & 2.58 & & 6.32 & & & & & \\
\hline $\begin{array}{l}\text { t-value } \\
\mu \alpha_{07-} \mu \alpha_{94}\end{array}$ & 0.18 & & & & & & & \\
\hline
\end{tabular}

\section{Model specification $\mathrm{H}$}

Allowing for different income elasticities of the cost parameter depending on the real income level, improves the log likelihood value of the model substantially. The income elasticity of the cost parameter is -1.3, and not significantly different from unity, for the high income segment. For the low income segment, the corresponding elasticity is only -0.3. As expected, the marginal disutility of cost is considerably higher in the low income segment than in the high income segment. Moreover, the average income elasticity increases to 0.80 , from 0.48 in model G, suggesting that not accounting for the impact of income on the elasticity biases this estimate.

Börjesson et al. (2012a) finds an analogous result when estimating the income elasticity of the value of time: the income elasticity of the value of time increases with income.

\section{Model specification I}

Neither $a_{07 I n c 1}$ and $a_{94 I n c 1}$ nor $a_{07 I n c 2}$ and $a_{94 I n c 2}$ are significantly different from each other and the log likelihood of model I does not improve significantly according to the chisquare test compared to model $\mathrm{H}$. Hence, the income elasticity of the cost parameter has remained stable at each real income level, which again suggests that the intertemporal and the cross-sectional income elasticity of the cost parameter are the same. 


\section{CONCLUSION}

How the travel time and cost parameters should be adjusted for future years is a central issue in travel demand forecasting, and the objective of this study is to provide some guidance on this point. The study is based on two essentially identical stated choice surveys carried out in 1994 and 2007 among drivers in Sweden, designed to measure the trade-off between travel time and travel cost. It is examined how the travel time and travel cost parameters have developed over the 14 years between the survey waves.

In travel demand forecasting models the response scale, inversely proportional to the variance of the error term (representing variables omitted in the utility function, including errors), is assumed to remain constant over time. For this reason, the objective of this study is, more precisely, to investigate how the travel time and travel cost parameters change over time under the assumption that the response scale remains constant. In all models estimated in this study, this assumption is thus made.

It is found that the mean of travel cost parameter has decreased significantly in real terms, while the mean of the travel time parameter has remained constant across the year-specific samples. The decline in the travel cost parameter can be explained entirely by higher average real incomes in the 2007 sample, compared to the 1994 sample. That is, when controlling for income in the model, the travel cost parameter is virtually identical between the year-specific samples. These results support evidence from earlier studies based on cross-sectional data, for instance Train and McFadden (1978), and with studies based on cross-sectional data collected a different points in time, for instance Fox (2011), suggesting that the travel cost parameter, rather than the time parameter, should be adjusted according to income.

In addition to the mean of the travel time parameter, year-specific parameters for inertia bias, loss aversion and standard deviation of the travel time and cost parameters also turn out to be virtually identical across years. Hence, the only yearspecific parameter that shows a non-negligible difference is the cost parameter. Moreover, when cross-sectional income differences are controlled for, the cost parameters for different income segments also become very similar. The fact that all parameters but the cost parameter remain so similar indicate that the response scale indeed is similar in the year-specific models. This seems plausible, since the surveys are virtually identical.

Under the assumption that the response scale has remained constant, the results imply that the marginal utility of travel cost had declined due to income growth, while the marginal utility of travel time has remained constant over time. Hence, it seems as though the increased possibility of using time more productively and more comfortable cars has not had any significant impact on the direct marginal disutility of travel time for the segment of drivers recruited in the survey. However, this may be different for travellers on other modes, where the possibility to use travel time more productively are larger than for drivers.

In summary, this study supports the recommendation to adjust the cost parameter, and not the time parameter, according to future income levels in forecasting. The question is then what income elasticity that should be applied inter-temporally.

This study suggests that the cross-sectional and inter-temporal income elasticity of the cost parameters is equal. This means that relevant cross-sectional income elasticity could be applied inter-temporally in forecasting models. This study also indicates that 
the elasticity of the income on the travel cost parameter is not constant but depends on real income level. For the sample of drivers with incomes above the median (pooled and fixed median for both samples), the income elasticity of travel cost parameter is above unity, -1.3 , but not significantly different from unity. For drivers with income below the median the income elasticity is lower -0.3 , implying that the average income elasticity is around 0.8 . These results thus suggest that the mean income elasticity will grow closer to unity, since an increasing share of drivers will belong to the high income group as the income levels increase in society.

\section{Acknowledgments}

I am indebted to Staffan Algers for help with data and to Jonas Eliasson and Staffan Algers for fruitful discussions. Financial support from the Swedish Road and Rail Administrations and VINNOVA and Centre for Transport studies, KTH, is also gratefully acknowledged. 


\section{REFERENCES}

Abrantes, P.A.L. and Wardman, M.R., 2011. Meta-analysis of UK values of travel time: An update. Transportation Research Part A 45(1), 1-17.

Algers, S., Lindqvist-Dillén, J., Widlert, S., 1995. The National Swedish Value of Time Study. Paper presented at the PTRC European Transportation Forum in Warwick 1995. Proceedings of seminar F, P393 ISBN 0-86050-283-X.

Amador, F.J., González, R.M. and Ortúzar, J.D., 2005. Preference heterogeneity and willingness to pay for travel time savings. Transportation 32(6), 627-647.

Axhausen, K.W., Hess, S., Konigb, A., Abayc, G., Bates, J,J. and Bierlaire, M., 2008. Income and distance elasticities of values oftravel time savings: New Swiss results. Transport Policy 15, 173-185.

Bateman, I., Munro, A., Rhodes, B., Starmer, C., Sugden, R., 1997. A test of the theory of reference-dependent preferences. The Quarterly Journal of Economics 112 (2), 479-505.

Badoe, D. and Miller. E., 1995. Analysis of the Temporal Transferability of Disaggregate Work Trip Mode Choice Models. Transportation Research Record, 1493, pp. 1-11.

Bates, J. and Whelan, G., 2001. Size and sign of Time Savings. ITS Working Paper no. 561.

Becker, G. S., 1965. A Theory of the Allocation of Time. The Economic Journal, 75(299), 493517.

Beser, M., and Algers, S., 2002. SAMPERS - The New Swedish National Travel Demand Forecasting Tool. In: Lundqvist, L., Mattsson, L.-G. (Eds.), National transport models: recent developments and prospects. Springer.

Bierlaire, M., 2003. BIOGEME: A free package for the estimation of discrete choice models . Proceedings of the 3rd Swiss Transportation Research Conference, Ascona, Switzerland.

Bierlaire, M., 2008. An introduction to BIOGEME Version 1.7, biogeme.epfl.ch.

Beesley, M. E., 1965, "The Value of Time Spent in Travelling: Some New Evidence", Economica, vol. 32, no. 126, pp. 174-185.

Börjesson, M., 2012. Valuating perceived insecurity associated with use of and access to public transport. Transport policy. Forthcoming.

Börjesson, M. and Eliasson J., 2012. Experiences from the Swedish Value of Time study. CTS Working paper 2012:8.

Börjesson, M., Fosgerau, M., Algers S., 2012a. On the income elasticity of the value of travel time. Transportation Research A. Volume 46, Issue 2, Pages 368-377.

Börjesson, M., Fosgerau, M., Algers, S., 2012. Catching the tail: Empirical Identification of Value of time Distribution. Transportation Research A. Volume 46, Issue 2, Pages 378-391.

Cameron, T. A. and James, M. D., 1987. Efficient Estimation Methods for "Closed-Ended" Contingent Valuation Surveys, Review of Economics and Statistics, vol. 69, no. 2, pp. 269-276.

Cherchi, E. and Ortúzar, J.de D., 2010. Can Mixed Logit infer the actual data generating process? Some implications for environmental assessment. Transportation Research D 15(7), 428-442.

Cirillo, C., Daly, A.J., Lindveld, K., 2000. Eliminating bias due to the repeated measurements problem. In: J.D. de Ortúzar, eds. Stated Preference Modelling Techniques. London: PTRC, 137-154.

Cirillo, C., and Axhausen, K. W., 2006. Evidence on the distribution of values of travel time savings from a six-week diary. Transportation Research Part A 40(5), 444-457.

Daly, A., Tsang, F., Rohr, C., 2011. The value of small time savings for non-business travel. Paper presented at the European Transport Conference, Glasgow. 
De Borger, B. and Fosgerau, M., 2008. A test of the theory of reference-dependent preferences: the trade-off between money and time. Journal of Urban Economics, Volume 64 (1), 101-115.

De Serpa, A.C., 1971. A theory of the economics of time, The Economic Journal, 81, 828-846.

Engelson, L and Svalgård, S., 1995. SYNERGETIC - The Travel Demand and Landuse Model for the Stockholm Region EMME/2 Implementation and Callibration Technique, presented at 4th European EMME/2 Users' Conference. http://www.inro.ca/en/pres_pap/european/eeug95/Europe01_1995.pdf

Evans, A. W., 1972. On the theory of the valuation and allocation and time. Scottish Journal of Political Economy, 19(1), 1-17.

Fox, J., 2011. Temporal transferability of mode-destination models: summary of literature, initial findings. Proceedings from the European Transport Conference.

Fox, J., and Hess, S., 2010. Review of Evidence for Temporal Transferability of ModeDestination Models. Transportation Research Record, 2175, pp 74-83.

Fosgerau, M., 2006. Investigating the distribution of the value of travel time savings. Transportation Research Part B, Vol 40 (8), 688-707.

Fowkes, A.S., 1999. Issues in Evaluation. A Justification for Awarding all Time Savings and Losses, both Small and Large, Equal Unit Value in Scheme Evaluation, in Accent/Hague op.cit., pp. 341-359.

Gunn, H., 2001. Spatial and Temporal Transferability of Relationships between Travel Demand, Trip Cost and Travel Time. Transportation Research E, Vol. 37, pp. 163189. 20

Gunn, H.F., Tuinenga, J.G., Cheung, Y.H.F. and Kleijn, H.J., 1999. Value of Dutch Travel Time Savings in 1997. Proceedings of the 8th World Conference on Transport Research, Vol 3, 513-526.

Hultkrantz, L. and Mortazavi, R., 2001. Anomalies in the Value of Travel-Time Changes", Journal of Transport Economics and Policy, vol. 35, no. 2, pp. 285-300.

Hess, S., Bierlaire, M., and Polak, J. W., 2005. Estimation of value of travel-time savings using mixed logit models. Transportation Research Part A 39(2-3), 221-236.

Jara-Diaz, S. R., and Guevara, S. R., 2003. Behind the Subjective Value of Travel Time Savings. Journal of Transport Economics and Policy 37, 29-46.

Jara-Díaz, S. R., 2003. On the goods-activities technical relations in the time allocation theory. Transportation, 30(3), 245-260.

Kahneman, D., Knetsch, J. L., and Thaler, R., 1990. Experimental Tests of the Endowment Effect and the Coase Theorem. Journal of Political Economy, vol. 98, no. 6, pp. 13251348.

Karasmaa, N. and Pursula. M., 1997. Transferability Analysis of Disaggregate Choice Models. Transportation Research Record, 1607, pp. 38- 44.

Mackie, P.J., Jara-Diaz, S.R. and Fowkes, A.S., 2001. The value of travel time savings in evaluation. Transportation Research Part E, Vol 37, 91-106.

McCarthy, P., 1982. Further Evidence on the Temporal Stability of Disaggregate Travel Demand Models. Transportation Research B, Vol. 16, No. 4, pp. 263-278.

Ramjerdi, F., Flügel, S., Samstad, H., and Killi, M., 2010. Value of time, safety and environment in passenger transport. Transportøkonomisk institutt. Retrieved from http://www.toi.no/article29726-29.html.

Román, C., Martín, J.C., Espino, R., Cherchi, E. Ortúzar, J. de D., Gonzales, R.M., Amador, F.J. and Rizzi, L.I., 2012. Valuation of travel time savings for intercity travel: the MadridBarcelona corridor. XVII Panamerican Conference. Santiago, Chile.

Silman, L., 1981. The Time Stability of a Modal-Split model for Tel-Aviv. Environment and Planning A, Vol. 13, pp. 751-762. 
Smith, V. L. and Walker, J. M., 1993. Monetary Rewards and Decision Cost in Experimental Economics. Economic Inquiry, XXXI, 245-61.

Tapley, N., Wardman, M., Gunn, H. and Hyman, G., 2007. Inter-Temporal Variations in Values of Time in Great Britain. Paper presented at the European Transport Conference.

Train, K., 1978. A Validation Test of a Disaggregate Mode Choice Model. Transportation Research, Vol. 12, pp. 167-174.

Train, K. and McFadden, D., 1978. The Goods/Leisure Tradeoff and Disaggregate Work Trip Mode Choice Models," TRANSPORTATION RESEARCH, 12, 349-353.

Wardman, M., 2001a. A review of British evidence on time and service quality valuations.Transportation Research Part E, Vol 37 (1-2), 107-128.

Wardman, M., 2001b. Inter-Temporal Variations in the Value of Time, ITS Working Paper 566, December 2001. 